\title{
On the Design and Performance Analysis of Printed Triangular Starred Array Strip Antenna
}

\author{
Adeniran A. O \\ Dept. of Physics, \\ University of Uyo, Uyo Akwa \\ Ibom State
}

\author{
Ekpo. S.S. \\ Dept. of Physics \\ University of Uyo, Uyo Akwa \\ lbom State
}

\author{
Ajao .O \\ Dept. of Science Lab Tech \\ Polytechnic of Ibadan
}

\begin{abstract}
In this paper, equilateral triangular microstrip star array antenna was designed for wireless communication applications. The antennas were modeled using microstrip lines, MTEEs and S parameter data for star arrayed triangular element .The data is extracted from the momentum simulation and combined with the microstrip transmission line. The properties of antennas such as bandwidth, gain, cross polar isolation and the return loss have been simulated. Since the resonant frequency is of these antenna is $2.0 \mathrm{GHz}$, these antenna is suitable for wireless network.
\end{abstract}

\section{Keywords}

Star triangular array, MTEEs, Microstrip, Agilent, and Cross polar

\section{INTRODUCTION}

Patch antennas are based on printed circuit technology to create flat radiating structure on top of a ground plane backed substrate. The advantage of such structures is the ability of building compact antennas with low manufacturing cost and high reliability. As electronics devices continue to shrink in size, the antenna designers is pushed to reduce the antenna size as well and the need to consider the effect of plastic (substrate) on the radiation patterns of the patches, since the electronics technology is moving to the use of plastic as the major electronics material, and also the advantages of plastic material (Adeniran A.O. 2012).

Nevertheless, improvements in the properties of dielectric materials and in design techniques have led to enormous growth in the popularity of Microstrip patch antennas, and there now a large number of commercial applications (Olaimat and Dib.2011,Bhartia and Jackson ). Many shapes of patches are possible, with varying applications, Many popular are rectangular, circular, triangular (equilateral, isosceles) and thin strip. Among the shapes that attracted much attention lately is the triangular shaped patch antenna most especially scalene triangular patch. This is due to their small size and complexity in their design but of more advantages over other shapes like triangular (isosceles and equilateral), circular, rectangular patch antennas. In this paper, the triangular patch antenna (TPA) was designed using cavity model and arrayed to form Star shape.. Up to our knowledge, this is the first time that these patches were considered. This paper is devoted to study the parameters of the TSPA.

\section{ANTENNA DESIGN PROCEDURES}

In this paper the TPAs are designed using cavity model, assuming perfect magnetic side walls, the resonant frequency is defined by (Jackson, 2005; Olaimat and Dib, 2011).

\section{SINGLE ELEMENT DESIGN}

A microstrip antenna element can be used alone or in combination with other like elements as part of an array. In either case, the designer should have a step by step element design procedure (Grag et al, 2001 and Yahya et al, 2012). Usually, the overall goal of a design is to achieve specific performance at a targeted frequency. The geometry of a single equilateral triangular is given by (Grag et al 2001, Olaimat \& Dib, 2011) as:

$$
f_{1,0}=\frac{2 c}{3 L \sqrt{\varepsilon_{r}}}
$$

A single element of equilateral patch geometry as shown in Figure 1, can be designed for the lowest resonant frequency using transmission line model.

$$
f_{1,0}=\frac{2 c}{3 a \sqrt{\varepsilon_{r}}}
$$

Where $c=3 \times 10^{8} \mathrm{~m} / \mathrm{s}$

$$
\begin{gathered}
\Delta L=0.412 h \frac{\left(\varepsilon_{e f f}+0.3\right)}{\left(\varepsilon_{\text {eff }}-0.258\right)} \frac{\left(\frac{W}{h}+0.264\right)}{\left(\frac{W}{h}+0.8\right)} \\
\varepsilon_{\text {eff }}=\frac{\varepsilon_{r}+1}{2}+\frac{\varepsilon_{r}-1}{2} \frac{1}{\left(1+12 \frac{h}{W}\right)^{-\frac{1}{2}}}
\end{gathered}
$$

For microstrip antennas the choice of the width of the patch radiator is very important. Small values of (W) result in low antenna efficiencies while large (W) values lead to higher order modes. The optimum values of $\mathrm{W}$ is

$W=\frac{\lambda_{o}}{2}\left(\frac{\varepsilon_{r}+1}{2}\right)^{-\frac{1}{2}}$

The resonant input resistance can be calculated from

$$
R_{\text {in }}\left(y=y_{o}\right)=\frac{1}{2\left(G_{1} \pm G_{12}\right.} \cos ^{2}\left(\frac{\pi y_{o}}{L}\right)
$$


$G_{1}=\frac{I_{1}}{120 \pi^{2}}$

$I_{1}=\int_{o}^{\pi}\left[\frac{\sin \left(\frac{k_{o} w}{2} \cos \theta\right)}{\cos \theta}\right]^{2} \sin ^{3} \theta$

$G_{12}=\frac{1}{120 \pi^{2}} \int\left[\frac{\sin \left(\frac{k_{o} w}{2} \cos \theta\right)}{\cos \theta}\right]^{2} j_{o}\left(k_{o} L \sin \theta\right) \sin ^{3} \theta d \theta$

$j_{o}=$ Bessel unction of the first kind order zero

The characteristic impedance of the line can be calculated from

$Z_{o}=\left\{\frac{60}{\sqrt{\varepsilon_{e f f}}} \ln \left[\frac{8 h}{w_{o}}+\frac{w_{o}}{4 h}\right]\right\}$ when $\frac{w_{o}}{h} \leq 1$

$\left\{\frac{120 \pi}{\sqrt{\varepsilon_{\text {eff }}}}\left[\frac{w_{o}}{h}+1.393+0.667 \ln \left(\frac{w_{o}}{h}+1.444\right)\right]\right\}$ when $\frac{w_{o}}{h}>1$

The values of L, W and inset feed (I) can be calculated using the above equations. Resonant frequency of $2 \mathrm{GHz}$ and equilateral triangular patches are arrayed in star form using ADS MTEEs and Microstrip lines to form the starred shaped microstrip patch as given in Figure 3 below.

\section{CALCULATION OF EQUILATERAL TRIANGLE}

Calculation of patch required some parameters for the values for the side to be obtained, the following are the parameters required for the determination of the sides for the patch antennas:

$\operatorname{Er}($ Dielectric constant $)=4.38$

$\mathrm{H}$ (height of the substrate) $=1.68 \mathrm{~mm}$

fr $($ resonant Frequency $)=2 \mathrm{GHz}$

$\mathrm{C}=$ speed of light

And the obtained sides are $5.4 \mathrm{~cm}$ and this are arranged in star formed using MTEE, M.Line and Couplers on ADS2009 platform and the simulation was done to obtain the Sparameters and the radiation pattern in 3D form for the starred triangular patch at $2 \mathrm{GHz}$.

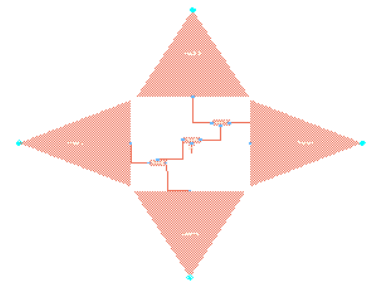

Figure 3: Triangular Starred Microstrip Patch Antenna
Figure 4: Triangular Starred Microstrip Patch Antenna on ADS2011 Platform

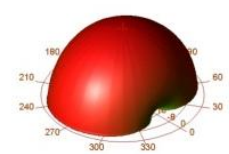

Figure 5: 3D Radiation Pattern for Triangular Starred Patch Antenna

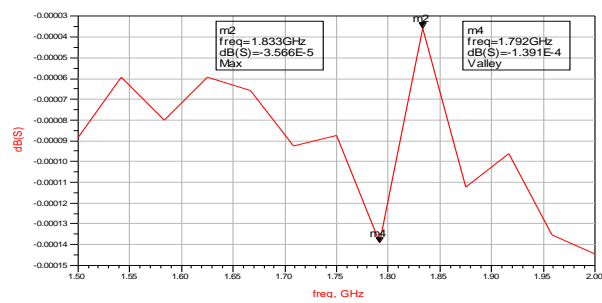

Figure 5: Return Loss for Triangular Starred Patch Antenna

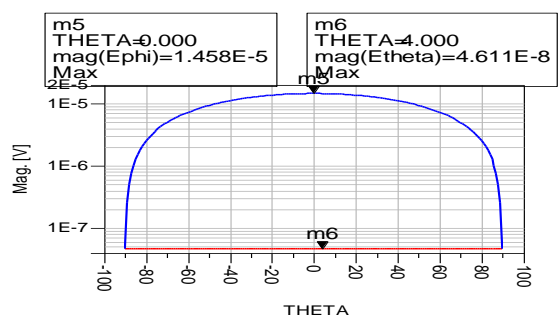

Figure 6: Electric (theta and Phi) field for Triangular Starred Patch Antenna

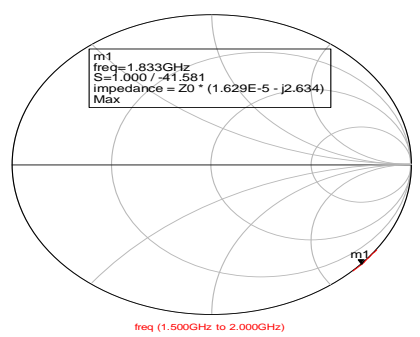

Figure 7: Impedance for Triangular Starred Patch Antenna

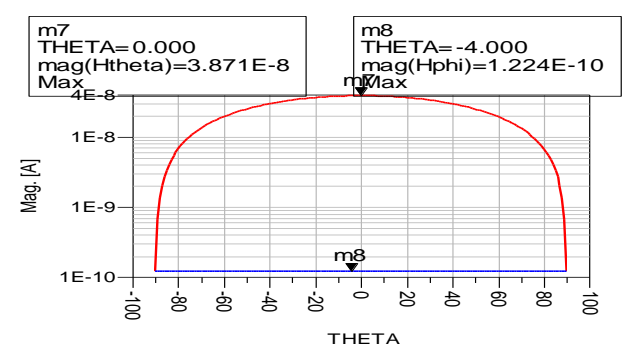

Figure 8: Radiation Pattern Magnetic (Theta and Phi) for Triangular Starred Patch Antenna 


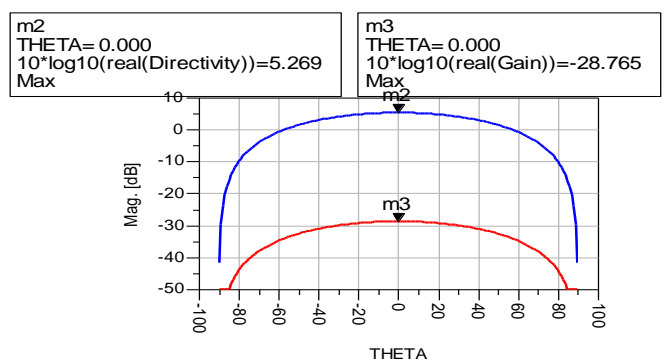

Figure 9: Gain and Directivity for Triangular Starred Patch Antenna

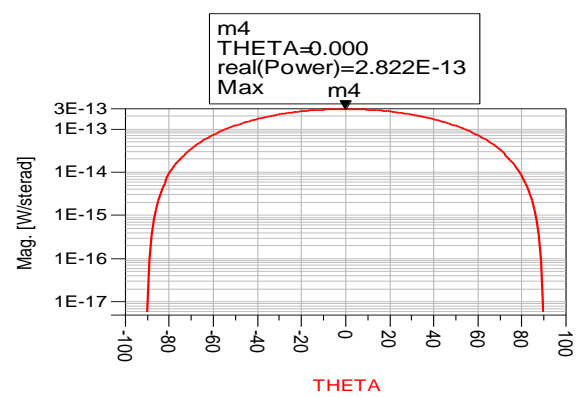

Figure 10: Power for Triangular Starred Patch Antenna

Table 1: Antenna Parameters for Triangular Starred Patch

\begin{tabular}{|c|c|}
\hline Parameters & Values \\
\hline Gain(dB) & -28.764 \\
\hline Directivity & $5.3 \mathrm{~dB}$ \\
\hline Return loss & $3.566 \mathrm{E}-5 \mathrm{~dB}$ \\
\hline Radiated power & $1.051 \mathrm{e}-12$ \\
\hline E-Phi & $1.458 \mathrm{E}-8$ \\
\hline E-theta & $4.611 \mathrm{E}-8$ \\
\hline H-Phi & $3.8657 \mathrm{e}-13$ \\
\hline H-theta & $1.22 \mathrm{e}-14$ \\
\hline
\end{tabular}

\section{CONCLUSION}

The design and performance analysis of triangular starred was simulated on ADS2000 platform and the parameters obtained shows the performance of the antenna at the frequency of $1.8 \mathrm{GHz}$, the directivity, Gain, Return Loss, Radiation in term of Magnetic and Electric as shown in Table 1.above are perfect and the obtained size for the antenna is printable on the televisions panel which make the gadget more small and compatible for people to use in their homes.

\section{REFERENCES}

[1] Agilent Software Inc. (2009): Advance Design System momentum simulator software.

[2] Adeniran A.O (2012) "Development of Scalene Triangular Microstrip Patch Antenna at $900 \mathrm{MHz}$

[3] Balanis C.A. (1997) Antenna Theory Analysis and Design Handbook. Second Edition, United States of America, John Willey \& Sons Inc. New York. p. 734.

[4] Bancroft .R. (2004) "Microstrip and Printed Antenna Design" Nobel Publishing, Chapter 2.

[5] Bhatia I. Bahl, P.R. Grag and Ittipiborn (2001) "Microstrip Antenna Design Handbook. Artech House: Boston.

[6] James J.R. and Hall P.S. (1989). The Handbook of Microstrip Antennas. Peter Peregrinus Ltd., London on behalf of the IEEE, Vol. $1 \& 2$.

[7] Kraus J. D, Marhefka R. J, Muuk B. A, Lehto A, Vainikainen P, Newman E. H, and Walker C (2002): Antennas for All Applications. Third Edition, ISBN: 007-232103-2, McGraw-Hill USA. Pp. 237 - 245.

[8] Lo. Y.T, Solomon D. and Richards W.F (2007) "Theory and Experiment on Microstrip Antennas "IEEE Transaction on Antennas and Propagation. Vol. AP-27 Pp 137-149.

[9] Jackson D.R. (2007). Microstrip Antenna. Chapter 7 of Antenna Engineering Handbook, J.L. Volakis (ed.). McGraw Hill.

[10] Olaimat .M.M and Dib .N. I (2011) “A Study of 15-7590 degree Angles Triangular Patch Antenna “.Progress In Electromagnetic Research Letters. Vol 2. Pp. 3 - 1

[11] D. Nowwatzky, (1963): Logarithimisch periodische Antennen.Technische Milleilungen des RFZ, Jahrg.7/Heft2, June 1963, pp.77-80, and Jahrg, 7/Heft3, Sept.1963, pp.127-133. (http://home.tonline.de/home/Dieter.Nowatzky/doc.htm)

[12] Greg and Yahya et al, (2004): Log Periodic Arrays .In the ARRL.Antenna Book [CD-ROM].The American Radio Relay League, Inc. Newington, CT06111-1494.

[13] B. Banic, and Hajach,P.(2000): Design and Simulation of Properties of Log Periodic Dipole Antenna" In Radioelekrionika ,Brastslava,12-16,Sept,2000,pp108109. 